compositor y Premio Nacional de Arte 2008, explica y hace oír su propia obra y comenta la trascendencia de la obra de Violeta Parra centrada en su canción El gavilán.

3. Taller de composición musical. Se efectuó el 18 de noviembre, a las 11:00 hrs. y 16:00 hrs. en el Conservatorio de Música UACH, a cargo del profesor Miguel Letelier.

Héctor Escobar

Director Conservatorio de Música UACH, Valdivia

\title{
Música chilena en el exterior
}

\section{Eduardo Cáceres en Uruguay}

El 3 de octubre, como un saludo al Coloquio Internacional sobre "Música/musicología y colonialismo" que se desarrolló en esos días en Montevideo, el Núcleo Música Nueva ofreció un concierto de cámara con obras de compositores latinoamericanos contemporáneos. En dicho concierto, que se llevó a efecto en la Sala Zitarrosa, se interpretó Cantos ceremoniales para aprendiz de machi de Eduardo Cáceres. La obra fue interpretada por el conjunto coral Kárpatia, que dirige Carlos Correa de Paiva.

Compositores chilenos en Argentina

La pianista Alexandra M. Aubert se presentó en Buenos Aires el 26 de noviembre, ofreciendo un concierto de música contemporánea en el CEAMC. En dicho recital incluyó Nueve relatos de Fernando García y A la búsqueda del ocaso infinito de Javier Pozo.

Compositores chilenos en Sevilla, España

El 27 de marzo de 2010 el guitarrista chileno Marcelo de la Puebla, en un concierto a beneficio de los damnificados por el terremoto ocurrido en Chile el 27 de febrero, ofreció, en la ciudad de Sevilla, el siguiente programa: Suite Victor Jara (estreno mundial), de Juan Antonio Sánchez, Sonata $\mathrm{N}^{\circ} 4$, de Gustavo Becerra, y Variaciones sobre un tema de Victor Jara, del cubano Leo Brouwer, obras, estas dos últimas, de las que se realizó su estreno sevillano. El programa se completaba con Amarguras, del compositor español Manuel Font de Anta, en una adaptación para guitarra de Marcelo de la Puebla. 